\title{
Waves in the Southern Great Barrier Reef
}

\author{
Jasmine B. D. Jaffrés ${ }^{1}$, Malcolm L. Heron ${ }^{1}$, Andrew Middleditch ${ }^{2}$, Craig R. Steinberg ${ }^{3}$, Tom H. Durrant ${ }^{4}$ \\ ${ }^{1}$ Marine Geophysical Laboratory, James Cook University, Townsville, Australia \\ ${ }^{2}$ Seaview Sensing Ltd, Sheffield, UK \\ ${ }^{3}$ Australian Institute of Marine Science, Townsville, Australia \\ ${ }^{4}$ Centre for Australian Weather and Climate Research, Bureau of Meteorology, Melbourne, Australia
}

\begin{abstract}
A brief description of three different platforms (WAVEWATCH III, Acoustic Doppler Current Profiler mooring and HF ocean radar) with directional wave measurement capabilities is provided. Initial results of directional wave and wind patterns derived from observations within the southern Great Barrier Reef, Australia, show consistency with the WAVEWATCH III model. These early findings are promising for future wind-wave investigations and validation studies in this region.
\end{abstract}

\section{INTRODUCTION}

The southern part of the Great Barrier Reef (GBR), Australia, is on a continental shelf which has a concave shape towards the southeast, facing into the prevailing wind and wave climate of the area. This is a dynamic area for waves from the open ocean, encountering the continental shelf edge and propagating up onto the shelf. This paper presents initial work to compare the WAVEWATCH III (WW3) model output with data from a wave-capable Acoustic Doppler Current Profiler (ADCP) mooring and HF ocean radar data in the area of the Capricorn and Bunker Groups of reefs and islands. Consistency is shown between the three different platforms, and this paper provides confirmation of the applicability of the WW3 model in the shallow waters of the continental shelf.

\section{WAVEWATCH III}

WW3, version 3.14, is a full-spectral third generation windwave model developed by NOAA/NCEP [1]. Here, its bathymetry is derived from DBDB2 (Digital Bathymetric Data Base), a 2-minute resolution grid produced by the Naval Research Laboratory (NRL) [2]. DBDB2 was converted to a WW3-compatible format using gridgen1.0, an automated mesh generation package developed specifically for WW3 by NOAA [3]. Optional forcing fields (i.e. wave and current forcing) are provided by spectral data assimilation and forecast model systems.
WW3 has one- and two-way nesting capabilities, which allow for higher resolution simulations in the areas of interest. In the present study, three nests have been set up (Table I), with the largest (Pacific-wide; $70^{\circ} \mathrm{S}-60^{\circ} \mathrm{N}, 130-260^{\circ} \mathrm{E}$ ) nest having a grid of $1^{\circ}$. The middle grid (Coral Sea; $8-35^{\circ} \mathrm{S}, 142-$ $165^{\circ} \mathrm{E}$ ) has a $0.5^{\circ}$ horizontal resolution. Both the Pacific and Coral grid are being forced by $0.5^{\circ}$ winds derived from Global Analysis and Spectral Prognosis (GASP), the global numerical forecast model operated by the Bureau of Meteorology [4].

The innermost grid (southern GBR; $21-24.5^{\circ} \mathrm{S}, 150-153.5^{\circ} \mathrm{E}$ ) has a $1 / 20^{\circ}$ horizontal resolution, and is being forced with MesoLAPS winds - a mesoscale version of the Australian Bureau of Meteorology's operational Limited Area Prediction System (LAPS) [5]. MesoLAPS has a horizontal resolution of $0.125^{\circ}$.

The nesting of the GBR grid with the two outer grids (Coral and Pacific) allows for the predominantly easterlysoutheasterly swell to move into the southern GBR. Thus, the wave model output is representing a combination of local wind waves and swells. Output parameters include significant wave height, as well as mean wave length, period and direction.

TABLE I

Grid characteristics of the wind-wave model WAVEWATCH III.

\begin{tabular}{|c|c|c|c|}
\hline grid/nest name & Pacific & Coral & GBR \\
\hline resolution $\left({ }^{\circ}\right)$ & 1 & 0.5 & 0.02 \\
\hline min. latitude $\left({ }^{\circ} \mathrm{N}\right)$ & -70 & -35 & -21 \\
\hline max. latitude $\left({ }^{\circ} \mathrm{N}\right)$ & 60 & -8 & -24.5 \\
\hline min. longitude $\left({ }^{\circ} \mathrm{E}\right)$ & 130 & 142 & 150 \\
\hline max. longitude $\left({ }^{\circ} \mathrm{E}\right)$ & 260 & 165 & 153.5 \\
\hline wind & GASP & GASP & MesoLAPS \\
\hline wind resolution $\left({ }^{\circ}\right)$ & 0.5 & 0.5 & 0.125 \\
\hline
\end{tabular}




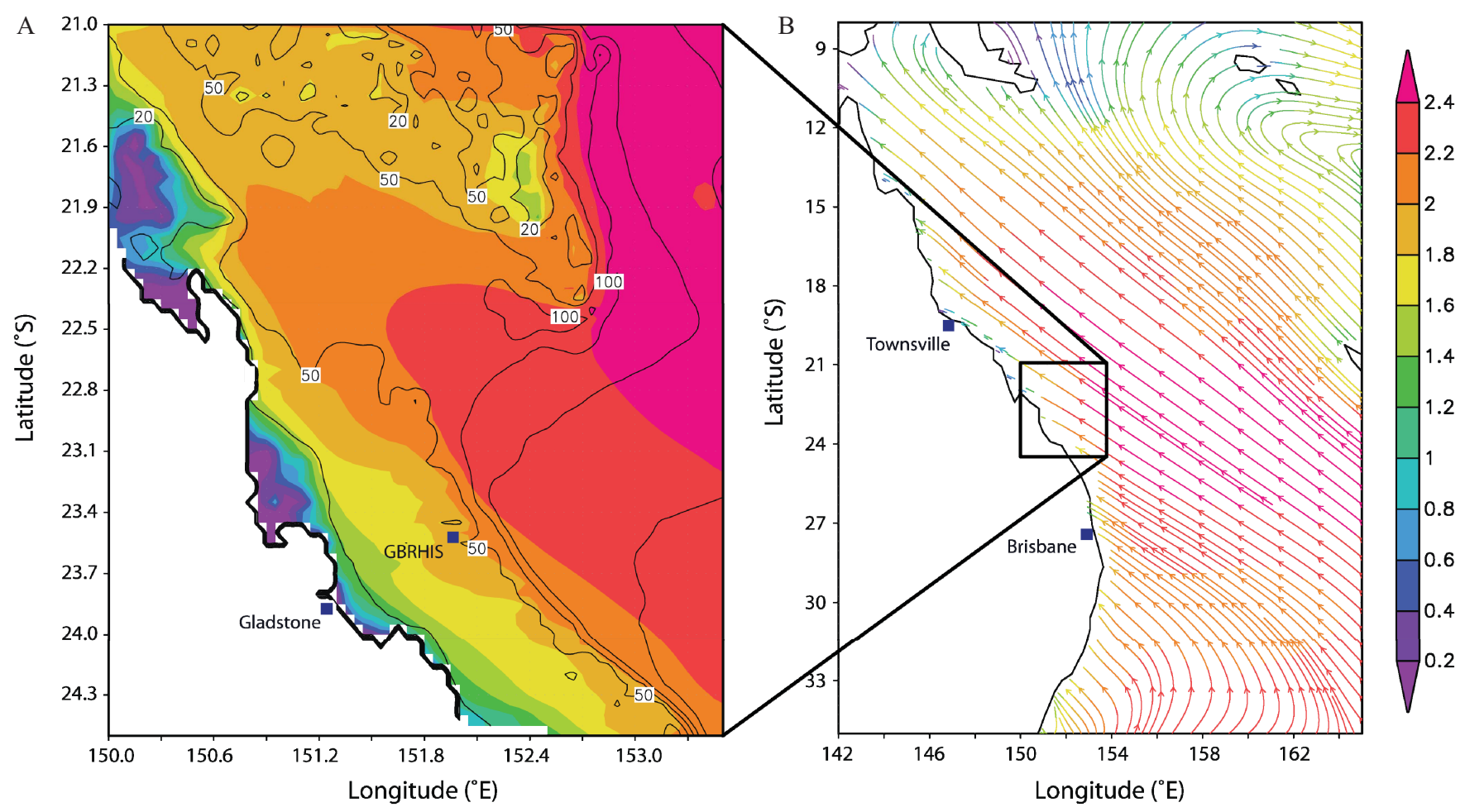

Figure 1A. Map of average significant wave height (m) superimposed on bathymetry contours, derived from WW3 for the period of March 17-31 2007. Also indicated is the location of the GBRHIS mooring, situated just to the south of Heron Island and to the west of One Tree Island. Figure1B shows the average wind direction over the same time period, predominantly southeasterlies, with the colour scheme also denoting significant wave height (m).

Some initial results from WW3 simulations are shown in Fig. 1. Generally, the largest significant wave heights occurred offshore, with the high waves to the northeast of the diagram being on the continental shelf. Wave heights are also greater within the Capricorn Channel when compared to the surrounding shallow bathymetry, potentially inducing a current towards the northwest within the channel.

\section{HF RADARS}

The WERA radar system in the southern GBR has been operational since November 2007. The HF radars, stationed at Tannum Sands (23 $\left.56.3^{\prime} \mathrm{S} ; 151^{\circ} 22.1^{\prime} \mathrm{E}\right)$ and Lady Elliot Island $\left(24^{\circ} 06.6^{\prime} \mathrm{S} ; 152^{\circ} 42.9^{\prime} \mathrm{E}\right)$, are used primarily to map surface currents over the continental shelf in this area. As a secondary parameter, the radars provide maps of significant wave height on a $4 \mathrm{~km}$ grid independently from each station for ranges up to $75 \mathrm{~km}$ from the stations. When data from two stations are combined - and with some time and space averaging - the radars can produce directional wave spectra $[6$, 7]. The optimum temporal averaging period is 1 hour, and the optimal spatial averaging is likely to be around $10 \mathrm{~km}$. Wind direction can be interpreted from HF radar data over the full coverage of grid points by adopting a general form for the directional spread. Phased array HF radars have the capability to map variations in the significant wave height field [8], with variations occurring due to wave setup when the waves were propagating in the direction opposing strong currents, and due to refraction [9].

WW3 has the capacity to include the effect of surface currents in its production of wave outputs. This feature is not often used because of the difficulty in getting surface current data. With the HF radar covering the area and providing hourly maps of surface currents, it is possible to drive the WW3 model with these data. The HF radar wave data implicitly includes the effects of surface currents, while these effects can be turned on or off in the WW3 model. This gives an accurate evaluation of the effects of currents on the wave field.

\section{ADCP MOORING}

The Great Barrier Reef Ocean Observing System (GBROOS) Heron Island South (GBRHIS) ADCP mooring ( $\left.23^{\circ} 30.8^{\prime} \mathrm{S} ; 151^{\circ} 57.3^{\prime} \mathrm{E}\right)$ is located to the south of Heron Island and west of One Tree Island (Fig. 1). GBRHIS is equipped with a Nortek Acoustic Doppler Wave and Current 


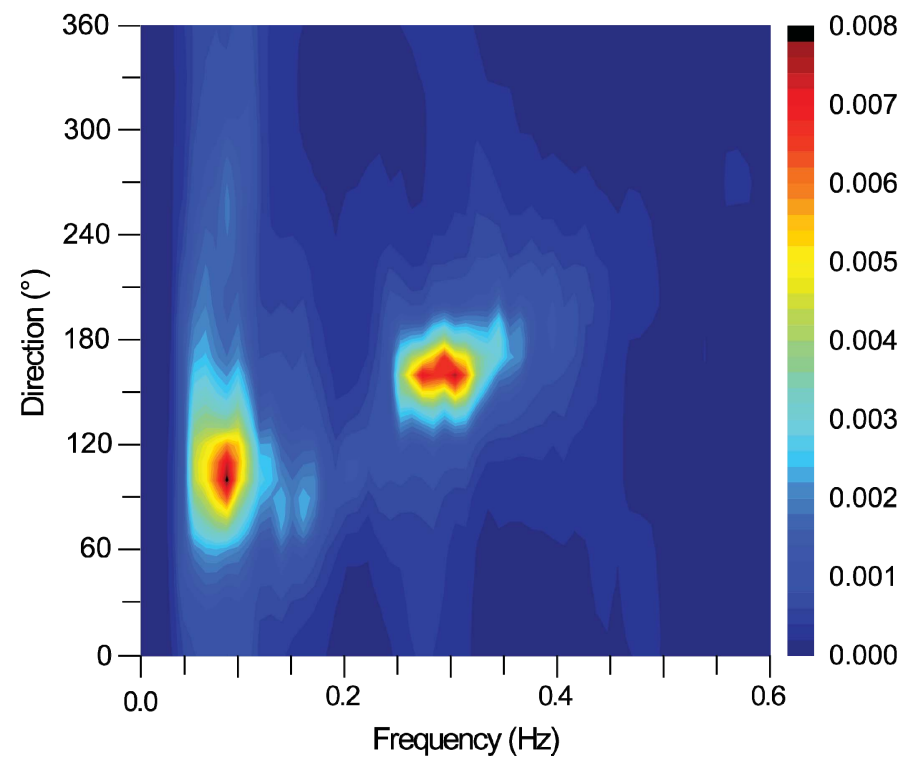

Figure 2. Directional wave spectrum $\left(\mathrm{m}^{2} / \mathrm{s}\right)$ from GBRHIS, derived with acoustic surface tracking by an AWAC. The waves, measured at 04:00, 30 April 2009 (UTC), display two distinct peaks. The local wind waves are predominantly from a south-southeasterly direction, whereas the lower frequency swell derives from the east-southeast.

Profiler (AWAC), which has directional wave measurement capability. The AWAC uses Acoustic Surface Tracking (AST) to monitor surface waves. At GBRHIS, the AWAC is located $10 \mathrm{~m}$ below the surface on top of a mooring, in a total depth of $46 \mathrm{~m}$, with output generated every two hours. A typical directional wave spectrum from GBRHIS is shown in Fig. 2.

\section{SENSORY WIND DATA}

Sensory wind data is a further means to validate wave fields obtained by WW3 and the HF radars. Sensory wind data are being collected at One Tree Island $\left(23^{\circ} 29.9^{\prime} \mathrm{S} ; 152^{\circ} 3.2^{\prime} \mathrm{E}\right)$ and Heron Island $\left(23^{\circ} 26.9^{\prime} \mathrm{S} ; 151^{\circ} 59.0^{\prime} \mathrm{E}\right)$, with data available since 20 November 2008 and 2 December 2008, respectively. Wind parameters, including mean wind speed and wind direction, are measured over 10-minute periods. In the southern GBR, southeasterly trade winds are predominant (Fig. 3) throughout most of the year.

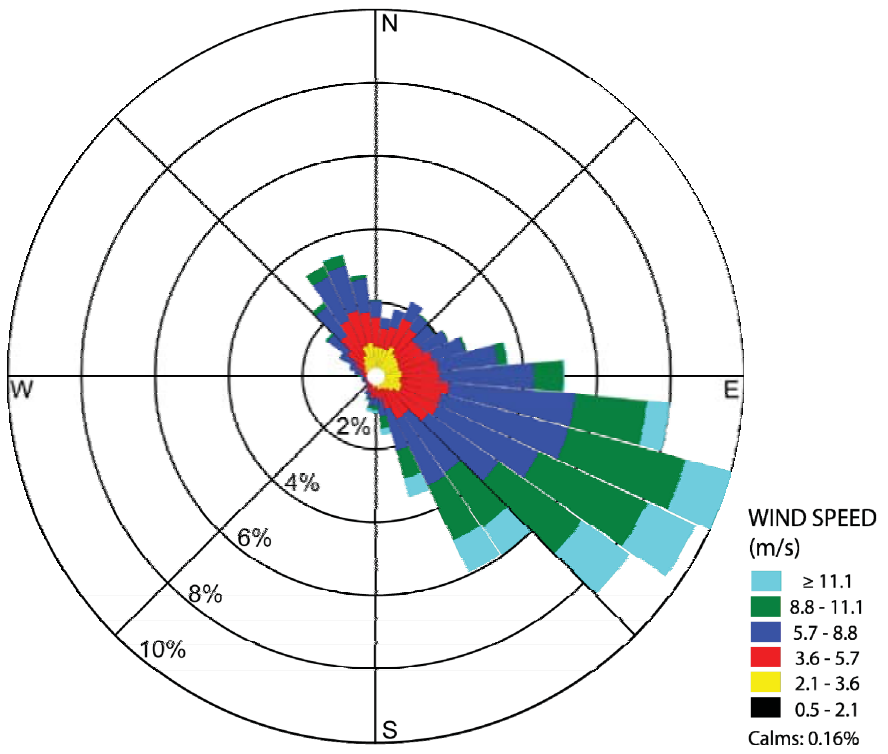

Figure 3. Accumulated sensory wind direction and speed for Heron Island (December 2008-October 2009), with the fields designating the direction of the incoming wind. Southeasterly trade winds are dominating the region, with a secondary peak being associated with northwesterly winds.

\section{CONCLUSION}

The consistency between the three independent directional wave measurement platforms is encouraging for future detailed validation studies of the WW3 model and the HF radar wave fields on the continental shelf in the southern GBR. Impending investigations will explore the extent of agreement of directional wave and wind fields derived from field observations (HF radar, ADCP mooring, wind sensors) and numerical modeling (WW3).

\section{ACKNOWLEDGMENT}

Data were sourced as part of the Integrated Marine Observing System (IMOS) - IMOS is supported by the Australian Government through the National Collaborative Research Infrastructure Strategy and the Super Science Initiative. It was obtained through the IMOS Ocean Data Portal www.imos.org.au. The research project is funded through an Industry Linkage Grant from the Australian Research council in collaboration with Seaview Sensing Ltd (UK) and Helzel Messtechnik GmbH (Germany). 


\section{REFERENCES}

[1] H.L. Tolman, User manual and system documentation of WAVEWATCH III ${ }^{T M}$ version 3.14: NOAA / NWS / NCEP / MMAB Technical Note 276, 2009.

[2] K. Marks, W. Smith, An evaluation of publicly available global bathymetry grids. Mar. Geophys. Res., vol. 27, pp. 19-34, 2006.

[3] A. Chawla, H.L. Tolman, Automated grid generation for WAVEWATCH III: NOAA / NWS / NCEP / MMAB Technical Note 254, 2007.

[4] R. Seaman, W. Bourke, P. Steinle, T. Hart, G. Embery, M. Naughton, et al., Evolution of the Bureau of Meteorology's global assimilation and prediction system. Part I: Analysis and initialisation. Aust. Met. Mag., vol. 44, pp. 1-18, 1995.

[5] K. Puri, G. Dietachmayer, G.A. Mills, N.E. Davidson, R.A. Bowen, L.W. Logan, The new BMRC Limited
Area Prediction System, LAPS. Aust. Met. Mag., vol. 47, pp. 203-23, 1998.

[6] L.R. Wyatt, Limits to the inversion of HF radar backscatter for ocean wave measurement. J. Atmos. Oceanic Technol., vol. 17, pp. 1651-66, 2000.

[7] L.R. Wyatt, A relaxation method for integral inversion applied to HF radar measurement of the ocean wave directional spectrum. Int. J. Remote Sens., vol. 11(8), pp. 1481 - 94, 1990.

[8] S.F. Heron, M.L. Heron, A comparison of algorithms for extracting significant wave height from HF radar ocean backscatter spectra. J. Atmos. Oceanic Technol., vol. 15, pp. 1157-63, 1998.

[9] B.K. Haus, R.J. Ramos, H.C. Graber, L.K.Shay, Z.R. Hallock, Remote observation of the spatial variability of surface waves interacting with an estuarine outflow. IEEE J. Ocean. Eng., vol. 31(4), pp. 835-49, 2006. 